\title{
A COMPARATIVE STUDY OF BENTHIC SOIL AT TWO DIFFERENT SITES OF HARDIA WETLAND OF SARAN DISTRICT OF NORTH BIHAR, INDIA
}

\author{
CHITRALEKHA SINHA
}

Department of Zoology, J. P. University, Chapra (Bihar)

\begin{abstract}
Soil is a dynamic body of nature that acquires properties in accordance with the forces which act upon it and within itself. It is a complete physical and biological system providing support, water, nutrients and oxygen to the plants. In the present study different soil quality parameters were analyzed i.e. temperature, conductivity, hydrogen ion concentration, total alkalinity, organic carbon and organic matter, total calcium, total magnesium, total sodium, total potassium, nitrate, ammoniacal nitrogen and available phosphorus from the soil of Hardia wetland.
\end{abstract}

Key words : Benthic soil, Physico-chemical characteristics, Nutrients dynamics, Biological \& chemical processes.

\section{INTRODUCTION}

In an aquatic ecosystem, soil is the chief storage of all the nutrients, which are made available to the water medium also. Soil, instead of being one thing, is in fact a complex thing, made up of several components viz. mineral-matter, water, air, organic-matter and living organisms. The structure and composition of soil along with its physical and chemical characteristics constitute edaphic factors, which influence not only the biotic community of the soil but also the entire aquatic community of the ecosystem. The investigation of Mitsch and Gosselink (1986) explains physico-chemical processes and nutrients dynamics of different wetland soil. Boers (1991) has studied the influence of $\mathrm{pH}$ on phosphate releases from the soils. Sinha et al. (1992) have studied the seasonal variation in physico-chemical properties of soil of Kawar lake. Gautam et al. (2011) have studied the soil condition of pond bottom of Hajipur (Bihar). Ignatieva (1993) has studied application of new functional model for calculation of phosphorus fluxes from sediments. Montigny and Praire (1993) have studied importance of biological and chemical processes in the release of phosphorus from a highly organic sediment. Present investigation is about benthic soil of Hardia wetland of Saran district.

\section{MATERIAL AND METHODS}

Physico-chemical analysis of Benthic Soil :

Conductivity : It was determined according to Trivedi and Goel (1984). Soil solution was prepared in 1:5 ratio and the conductivity value was recorded immediately with the help of conductivity bridge. The value was expressed in micro siemans $/ \mathrm{cm}$.

Hydrogen ion concentration $(\mathbf{p H}): \mathrm{pH}$ of soil suspension $(1: 5)$ was determined with the help of Griph $\mathrm{pH}$ meter according to Trivedi and Goel (1984) method.

Alkalinity : Total alkalinity was determined by titration of soil solution (1:5) with strong acid (0.1 NHCL) as Trivedi and
Goel (1984) using phenolphthalein and methyl orange as indicator. Phenolphthalein alkalinity denotes the value of carbonate. If the solution remains colorless on adding phenolphthalein then phenolphthalein alkalinity is zero. Now methyl orange alkalinity was determined which gives the value of total alkalinity.

Calculation :

Total alkalinity $=(\mathrm{ml} \times \mathrm{N}$ of HCL $\times 500 / \mathrm{ml}$ of soil solution $)$

Organic matter : Organic matter of the soil was determined by modified Walkley and Black method (Trivedi and Goel, 1984). The organic matter of the soil was digested with the excess of $\mathrm{K}_{2} \mathrm{CR}_{2} \mathrm{O}_{7}$ and $\mathrm{H}_{2} \mathrm{SO}_{4}$. The unutilized was then titrated against ferrous ammonium sulphate.

Calculation : Percent organic matter $=3.951 / \mathrm{g}(1-\mathrm{t} / \mathrm{s}) \times 1.724$ Where, $\mathrm{g}=$ weight of sample in $\mathrm{gm}$.

$\mathrm{s}=\mathrm{ml}$ of ferrous solution with blank $\mathrm{t}=\mathrm{ml}$ of ferrous solution with sample solution.

Organic carbon : It was calculated as follows:

Percent Carbon $=$ Percent organic matter $/ 1.724$

Chloride : It was estimated argento titrimetrically using potassium chromate as indicator and $\mathrm{AgNo}_{3}$ as titrant (Trivedi and Goel,1984) of the soil suspension (1:5)

Calculation : $\mathrm{Cl}(\mathrm{mg} / 100 \mathrm{~g})=$

$\left(\mathrm{ml} \times \mathrm{N}\right.$ of $\left.\mathrm{AgNo}_{3} \times 35.5 \times 1000\right) /\left(\mathrm{ml}\right.$ soil $\left.\mathrm{Sol}^{\mathrm{n}} \times 2\right)$

Total calcium and total magnesium : It was determined by titrimetric method using EDTA as titrant and calcium hardness tablet as indicator (Trivedi and Goel,1984). $50 \mathrm{~g}$ of air dried soil sample was mixed with $100 \mathrm{ml}$ of ammonium acetate solution. The suspension was kept overnight and then filtered through Whatman filter paper (number 50). The filtered was titrated against EDTA solution. For total magnesium, first total hardness was determined and from its value of hardness was subtracted.

Calculation :

$\mathrm{Ca}^{2+}(\mathrm{mg} / 100 \mathrm{~g})=(\mathrm{A} \times 400.8 \mathrm{XV}) / \mathrm{v} \times \mathrm{s} \times 10$

$\left.\mathrm{Mg}^{2+}(\mathrm{mg} / 100 \mathrm{~g})=[(\mathrm{B}-\mathrm{A}) \times 400.8 \mathrm{XV}) / \mathrm{v} \times 1.645 \mathrm{x} \mathrm{s} \times 10\right]$ 
Where;

$\mathrm{A}=$ Volume of EDTA used for calcium determination.

$\mathrm{B}=$ Volume of EDTA used for calcium and magnesium determinant.

$\mathrm{V}=$ Total volume of soil extract prepared $(500 \mathrm{~g})$

$\mathrm{s}=$ Weight of $\operatorname{soil}(50 \mathrm{~g})$

$\mathrm{v}=$ Volume of soil extract titrated.

Nitrate : For estimation of nitrate $50 \mathrm{~g}$ of dry soil was taken in a flask and to which $250 \mathrm{ml}$ of Nitrate extraction reagent was added. The solution was mixed for 15 minutes. Then $0.5 \mathrm{ml}$ of calcium hydroxide was added to the mixture and the solution was mixed further for 5 minutes. Now $1 \mathrm{~g}$ of $\mathrm{MgCo}_{3}$ was added and mixed. The content was filtered through a filter paper (Whatman number 50) and the total volume of titrate was measured. The nitrate content of filtered was determined spectrophotometrically.

Nitrate $(\mathrm{mg} / 100 \mathrm{~g})=\mathrm{F} \times \mathrm{V} / 10 \times \mathrm{S}$

Where;

$\mathrm{F}=$ Nitrate determined in filtrates

$\mathrm{V}=$ Total volume of filtrate $(\mathrm{ml})$

$\mathrm{S}=\mathrm{Wt}$. of soil taken $(\mathrm{g})$

Ammonium nitrogen : $100 \mathrm{gm}$ of fresh soil sample was taken in a $500 \mathrm{ml}$ conical flask and mixed with $200 \mathrm{ml}$ of acidified Nacl solution. After 30 minutes the suspension was filtered through Whatman number 42 filter paper. The conical flask was rinsed with $500 \mathrm{ml}$ of Nacl solution and rinsing was poured into the soil.

Soil was also leached with extra $200 \mathrm{ml}$ of Nacl. The volume leached was raised to $500 \mathrm{ml}$ with acidified $\mathrm{Nacl} \mathrm{Sol}^{\mathrm{n}}$. Now calibration curve was prepared by placing aliquots of diluted standard (ranging betwee $4 \mathrm{n} 3-30 \mathrm{ml}$ ) in a series of 100 $\mathrm{ml}$ Volumetric flasks. $2 \mathrm{ml}$ of Sodium tartarate solution and 50 $\mathrm{ml}$ of acidified Nacl solution was added to it and final volume was raised to $90 \mathrm{ml}$ with distilled water. Now $5 \mathrm{ml}$ of Nessler's reagent was mixed thoroughly and again volume of the content was raised to $100 \mathrm{ml}$. Finally percentage transmission was observed at $410 \mathrm{~nm}$. Calibration curve was prepared by plotting percentage transmission against concentration on a linear scale. Soil extract was also prepared for estimation of Ammonium as described above except acidified Nacl was not added.

\section{Calculation :}

Ammoniacal nitrogen $(\mathrm{mg} / 100 \mathrm{~g})=10 \mathrm{x} \mathrm{mg}$ from curve

Available phosphorus : For estimation of available phosphorus $1 \mathrm{gm}$ of air dried soil was taken in a flask and to it $200 \mathrm{ml}$ of $0.002 \mathrm{NH}_{2} \mathrm{SO}_{4}$ was mixed. The suspension was shacked for 40 minutes and filtered through Whatman number 50 filter paper. The concentration of phosphorus in filtrated was obtained.

\section{Calculation :}

Available phosphorus $(\mathrm{mg} / 100 \mathrm{~g})=\mathrm{mg} \mathrm{P} / 1$ in soil extract $\mathrm{x}$ 1000/50.

\section{RESULTS AND DISCUSSION}

Temperature : It was recorded between $17^{\circ} \mathrm{C}$ (site B) and $27.4^{\circ} \mathrm{C}$ (site A) in the month of Dec.,2012 \& June,2012 respectively. Soil temperature was recorded highest during summer followed by monsoon and winter respectively during the first year of study while during second year it was in highest range during monsoon followed by summer and winter respectively. Average value varied between $17.9^{\circ} \mathrm{C} \& 25.9^{\circ} \mathrm{C}$ (Fig. 1 ).

Conductivity : It was recorded between $190 \mu \mathrm{s} / \mathrm{cm}$ (site B) and $820 \mu \mathrm{s} / \mathrm{cm}$ (site A). The highest conductivity was recorded in winter followed by summer and monsoon respectively during first year of study while it was highest in summer followed by winter and monsoon in the second year followed by monsoon and winter respectively. The mean value of conductivity varied from $200-780 \mu \mathrm{s} / \mathrm{cm}$ (Fig.2).

Hydrogen ion concentration : It was recorded in the slightly acidic range between 5.0 site A \& 6.8 site B in the month of Dec.,2011 \& Oct.,2013 respectively. The lowest $\mathrm{pH}$ value was recorded during summer month. The mean value fluctuated from $5.7 \& 6.5$ (Fig. 3 ).

Total alkalinity : It was recorded between $0.20 \mathrm{~m} \mathrm{eq} / 100 \mathrm{~g}$ (Dec.,2011) \& $2.84 \mathrm{~m} \mathrm{eq} / 100 \mathrm{~g}$ (Aug.,2013) at site B. Increasing trend was observed during Nov.,2011 \& May,2012 in the first year again between Nov.,2012 and Aug.,2013 during the second year of study. The mean value varied between $0.26 \mathrm{~m} \mathrm{eq} / 100 \mathrm{~g} \& 2.82 \mathrm{~m} \mathrm{eq} / 100 \mathrm{~g}$ (Fig.4).

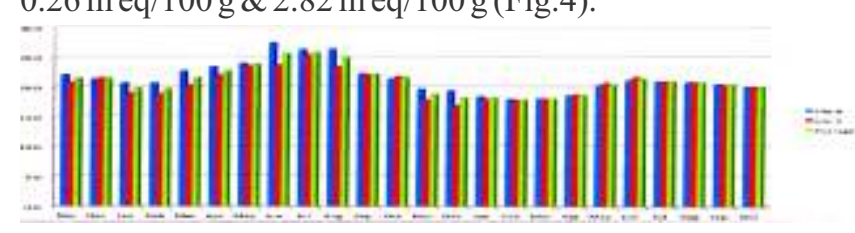

Fig. 1 Monthly variation in temperature $\left({ }^{\circ} \mathrm{C}\right)$ of soil of Hardia wetland (November,2011-October,2013).

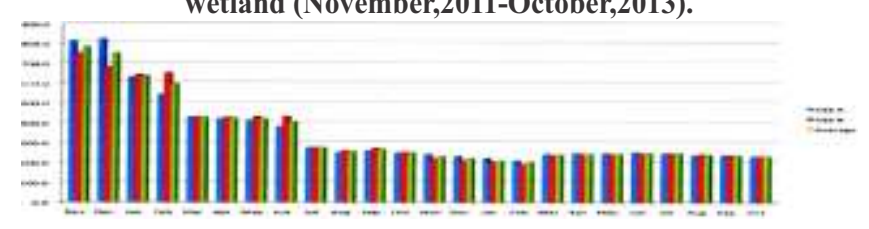

Fig. 2 Monthly variation in conductivity of soil of Hardia wetland (November,2011-October,2013).

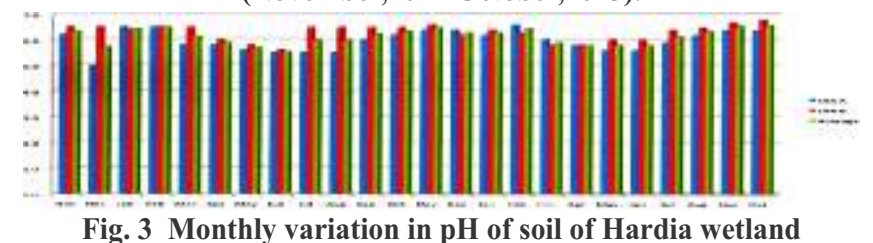

Fig. 3 Monthly variation in pH of soil of Hardia wetland (November,2011-October,2013).

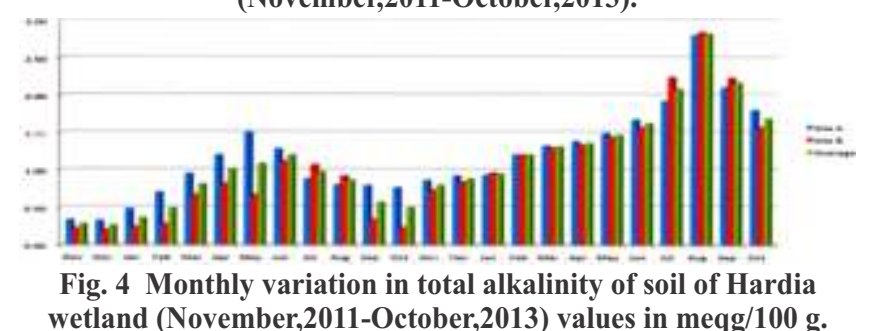


Organic carbon and organic matter : An increasing trend in the quantity of both organic carbon and matter was observed during January-June and decreasing trend during monsoon to winter of the first year was observed and again similar trend during the second year of study was observed. The $\%$ organic content were recorded between 2.05\% (Dec.,2011) and $17.45 \%$ (June,2012) at site B \& site A respectively. The mean value was between $2.10 \% \& 16.71 \%$ (Fig.5).

Similar trend of fluctuation was recorded in the organic matter content. Its mean value ranged between $3.62 \%$ and $28.83 \%$ (Fig.6).

Total calcium : The soil of the wetland is quite rich in calcium content. It was recorded between $582.06 \mathrm{mg} / 100 \mathrm{~g}$ (Dec., 2011) \& $801.50 \mathrm{mg} / 100 \mathrm{~g}$ (October,2012) at site B and site A respectively. Total calcium increased from January-June and again from March-July during second year of study (Fig.7).

Total magnesium : It was recorded between $24.00 \mathrm{mg} / 100 \mathrm{~g}$ (Jan.,2012) \& $220.92 \mathrm{mg} / 100 \mathrm{~g}$ (Aug.,2012). It showed increasing trend from Jan.-Aug. and then decreasing up to Feb. and a further increase up to July. The mean value ranged from $30.49 \mathrm{mg} / 100 \mathrm{~g}$ to $156.85 \mathrm{mg} / 100 \mathrm{~g}$ (Fig. 8 ).

Total sodium : In summer and monsoon of both the year it showed increasing trend while in winter its value showed decreasing trend. Its value ranged between $24.29 \mathrm{mg} / 100 \mathrm{~g}$ (site B) \& $32.06 \mathrm{~g} / 100 \mathrm{~g}$ (site B) during the months of Feb.,2012 and Aug.,2012 respectively. The average value ranged between $25.30 \mathrm{mg} / 100 \mathrm{~g} \& 31.55 \mathrm{mg} / 100 \mathrm{~g}$ of soil (Fig.9).

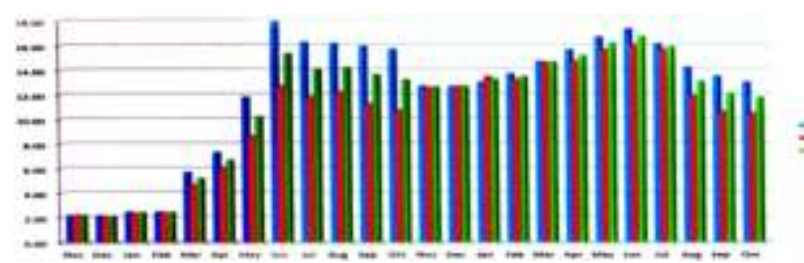

Fig. 5 Monthly variation in organic carbon content of soil of Hardia wetland (November,2011-October,2013) value in percent.

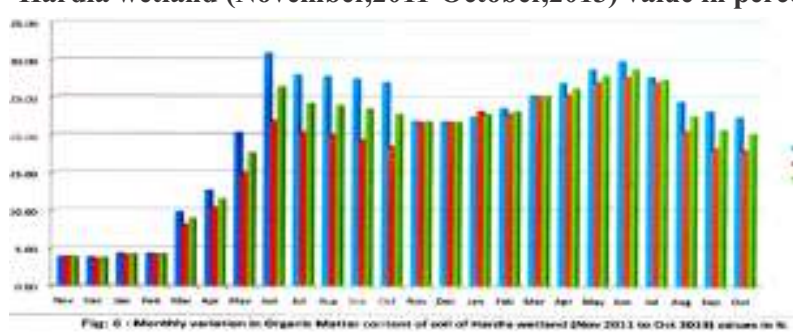

Fig. 6 Monthly variation in organic carbon content of soil of Hardia wetland (November,2011-October,2013) value in percent.

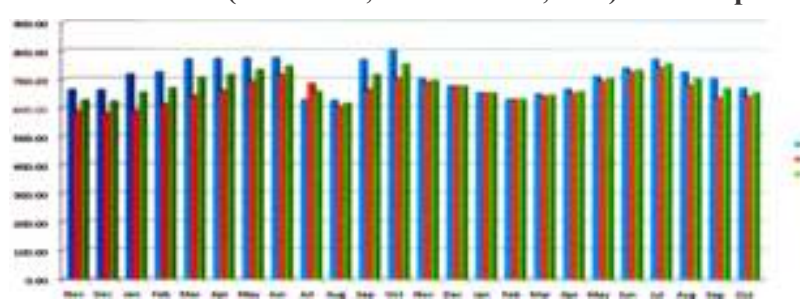

Fig. 7 Monthly variation in total calcium content of soil of Hardia wetland (November,2011-October,2013) value in $\mathbf{m g} / 100 \mathrm{mg}$.
Total potassium : An increasing trend during summer up to middle monsoon while decreasing trend were observed during winter of both the year of study. Its value ranged from $68.40 \mathrm{mg} / 100 \mathrm{~g}$ (Feb.) to $141.91 \mathrm{mg} / 100 \mathrm{~g}$ (Aug.) at site A during first year. It was in lower range during second year of study. Its mean value ranged from $68.41 \mathrm{mg} / 100 \mathrm{~g}$ to 140.91 $\mathrm{mg} / 100 \mathrm{~g}$ of soil (Fig. 10).

Nitrate : An irregular trend in the fluctuation of nitrate content was recorded. It ranged between $61.0 \mathrm{mg} / 100 \mathrm{~g}$ (site A) and $286.0 \mathrm{mg} / 100 \mathrm{~g}$ (site B) during Sep.,2012 and Dec.,2012. Its average value ranged between $62.2 \mathrm{mg} / 100 \mathrm{~g} \& 270.5$ $\mathrm{mg} / 100 \mathrm{~g}$ of soil (Fig.11)

Ammoniacal nitrogen : Lower values were recorded during summer months while upward trend was recorded during monsoon months. Its value ranged between $30.00 \mathrm{mg} / 100 \mathrm{~g}$ (Feb.) and $87.0 \mathrm{mg} / 100 \mathrm{~g}$ (Nov.) at site A. Average values varied between $32.5 \mathrm{mg} / 100 \mathrm{~g} \& 84.2 \mathrm{mg} / 100 \mathrm{~g}$ of soil (Fig.12).

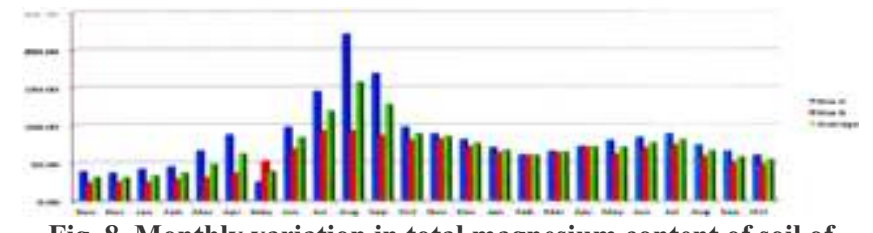

Fig. 8 Monthly variation in total magnesium content of soil of Hardia wetland (November,2011-October,2013) value in $\mathrm{mg} / 100 \mathrm{~g}$

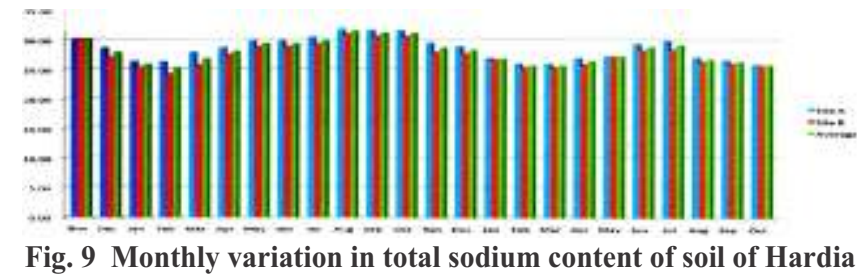

Fig. 9 Monthly variation in total sodium content of soil of Hardia wetland (November,2011-October,2013) value in $\mathrm{mg} / 100 \mathrm{mg}$.

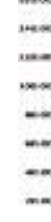

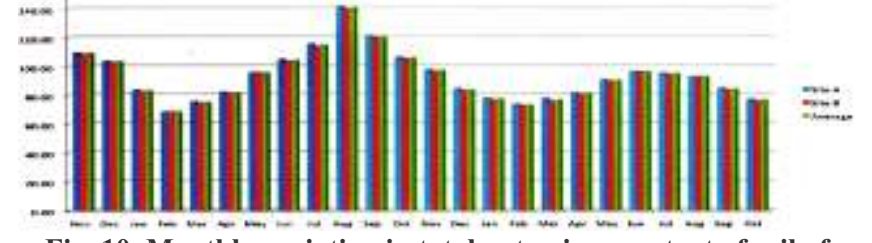

Fig. 10 Monthly variation in total potassium content of soil of Hardia wetland (November,2011-October,2013) value in $\mathrm{mg} / 100 \mathrm{~g}$.

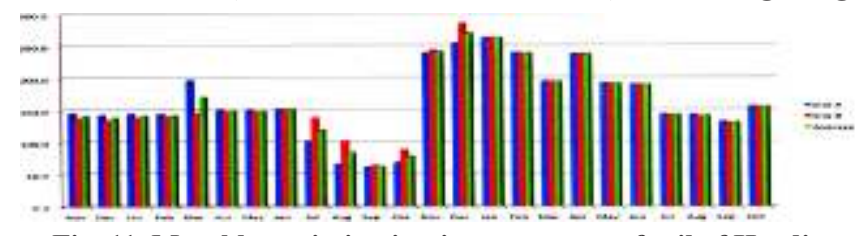

Fig. 11 Monthly variation in nitrate content of soil of Hardia wetland (November,2011-October,2013) values in $\mathrm{mg} / 100 \mathrm{~g}$.

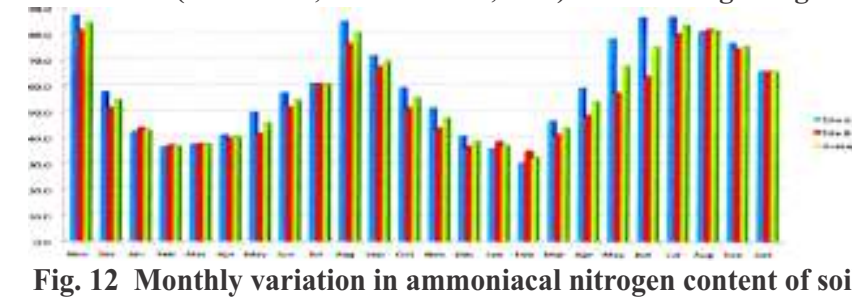

Fig. 12 Monthly variation in ammoniacal nitrogen content of so
of Hardia wetland (Nov.,2011-Oct.,2013) value in $\mathrm{mg} / 100 \mathrm{~g}$. 
Available phosphorus : Its content was very poor and it varied from $2.20 \mathrm{mg} / 100 \mathrm{~g}$ (site B) to $7.10 \mathrm{mg} / 100 \mathrm{~g}$ (site A). It showed gradual increase during summer while decreased irregularly during rest of the seasons in both the year of study. The mean value was recorded in the range of $2.90 \mathrm{mg} / 100 \mathrm{~g}$ to $5.71 \mathrm{mg} / 100 \mathrm{~g}$ of soil (Fig.13).

The soil of the wetland is alluvial loam in texture. It is

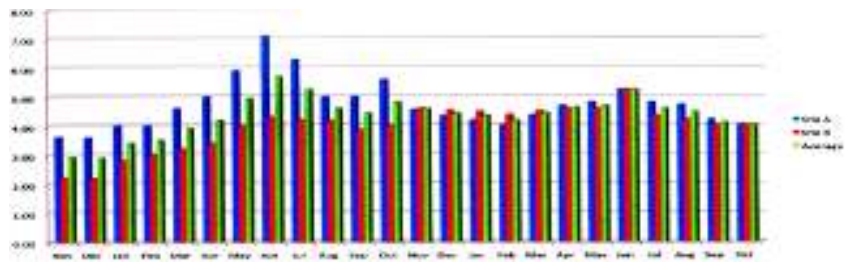

Fig. 13 Monthly variation in available phosphorus content of soil of Hardia wetland (Nov.,2011-Oct.,2013) values in $\mathrm{mg} / 100 \mathrm{~g}$. rich in humus and calcium content. Soil and water temperature showed similar fluctuation trend due to low water level. Conductivity of the soil was very high. It is also supported by the idea of Richardson et al. (1978). Soil is acidic due to excessive decomposition Mitsch \& Gosselink (1986) and Jhingran et al. (1991) also support the above idea. The increase in total alkalinity of soil is due to decomposition of molluscan shells. Increase in the level of organic matter and organic carbon is due to accumulation of decomposing material on the soil surface, the increase in total calcium is due to decomposing plants, animal and molluscan shells. The winter and monsoon decrease of total magnesium is due to its rapid utilization by producer autotrophs \& increase is due to decomposing biota. Decrease during winter and monsoon of total sodium, total potassium is due to its utilization by biota. Lower level of nitrate during monsoon is due to rains. Increase of phosphorus during summer is due to decomposition of organism and excreta.

\section{REFERENCES}

Boers, P. C. M. (1991). The influence of $\mathrm{pH}$ on phosphate release from sediments. Wat. Res., 25 : 309-311.

Gautam, A.; Singh, V. S. and Kumar, Satyendra (2011). Studies on soil condition of pond bottom of Hajipur (Bihar). Biospectra, 6(1) : 93-96.

Ignatieva, N. V. (1993). Application of new functional models for calculation of phosphorus fluxes from sediments. Hydrobiol., 253 : 319 322.

Jhingran, V.G. (1991). Fish and fisheries of India. Hindustan Publishing corporation. Delhi, p. 727.

Mitsch, W. J. and Gosselink, J. G. (1986). Wetlands. Van Nostrand, Reinhold, New York, p. 539.

Montigny, C. and Praire, Y. (1993). The relative importance of biological and chemical process in the release of phosphorus from a highly organic sediment. Hydrobiol., $253: 141-150$.

Richardson, C. J.; Tilton, D. J.; Kadlec, J. A.; Chamie, J. P. M. and Wentz, W. A. (1978). Nutrient dynamics of Northern wetland.

Sinha, A. K.; Singh, D. K.; Baruah, A. and Sharma, U. P. (1992). Seasonal variation of physico-chemical properties of bottom sediments of Kawar lake, Begusarai (Bihar). J. Freshwater Biol., 4(4) : 249-254.

Trivedi, R. K. and Goel, P. K. (1984). Chemical and biological methods for water pollution studies. Environmental Publ., Karad, India, p. 250. 